\title{
Spatial interpolation techniques for climate data in the GAP region in Turkey
}

\author{
Halit Apaydin*, F. Kemal Sonmez, Y. Ersoy Yildirim \\ Department of Farm Structures and Irrigation, Faculty of Agriculture, University of Ankara, 06110 Diskapi, Ankara, Turkey
}

\begin{abstract}
Six spatial interpolation techniques (inverse distance weighted, global polynomial interpolation, local polynomial interpolation, completely regularized spline, kriging and cokriging with 4 sub-types) were evaluated to determine the best spatial distribution of 6 different climate parameters (solar radiation, sunshine duration, temperature, relative humidity, wind speed and rainfall) in the region of the Southeastern Anatolia Project (GAP) of Turkey. Based on the root mean square error values of predictions made using measured values from 1971 to 1999, simple cokriging yielded the best results for temperature, solar radiation, relative humidity, wind speed and completely regularized spline for sunshine duration and rainfall.
\end{abstract}

KEY WORDS: Spatial interpolation · Climate - Southeastern Anatolia Project · Inverse distance weighted $\cdot$ Polynomial interpolation $\cdot$ Kriging $\cdot$ Cokriging $\cdot$ Completely regularized spline

\section{INTRODUCTION}

Meteorological variables required for applications in hydrology and water resources management are usually measured at meteorological stations, and the data are only valid for the point where it is measured. Spatial interpolation can be used to estimate meteorological variables at other locations. Although there are several methods to perform this, it can be difficult to determine which one best reproduces actual conditions. Each method's advantages and disadvantages depend strongly on the characteristics of the data set: a method that fits well with some data can be unsuitable for a different set of data. Thus, criteria must be found to decide whether the method chosen is suited for the point data set. It is also important to specify the aims of the interpolation, because different aims can require different criteria for evaluation of the interpolation (Borga \& Vizzaccaro 1997, Caruso \& Quarta 1998, Campling et al. 2001).

The correct determination of the spatial distribution of meteorological variables is as important as their measurement. Depending on the spatial attributes of the data, the accuracy of the results may vary widely among spatial interpolation methods. The choice of spatial interpolator is especially important in mountainous regions with fewer data, where the values of variables may change over short spatial scales (Collins 1996).

We compared 6 spatial interpolation techniques for 6 climate variables (solar radiation, sunshine duration, temperature, relative humidity, wind speed and rainfall) to determine the best climatic surface generation method for the Southeastern Anatolia Project (GAP) region (Fig. 1). The interpolation techniques were: inverse distance weighted (IDW), global polynomial interpolation (GPI), local polynomial interpolation (LPI), completely regularized spline (CRS), kriging and cokriging with 4 sub-types.

\section{BACKGROUND}

Interpolation of point data was mainly performed for rainfall data. The simplest and most common method is the Thiessen (1911) polygon method, which uses a polygon of influence around each gauge with the boundaries at a distance halfway between gauge pairs. 


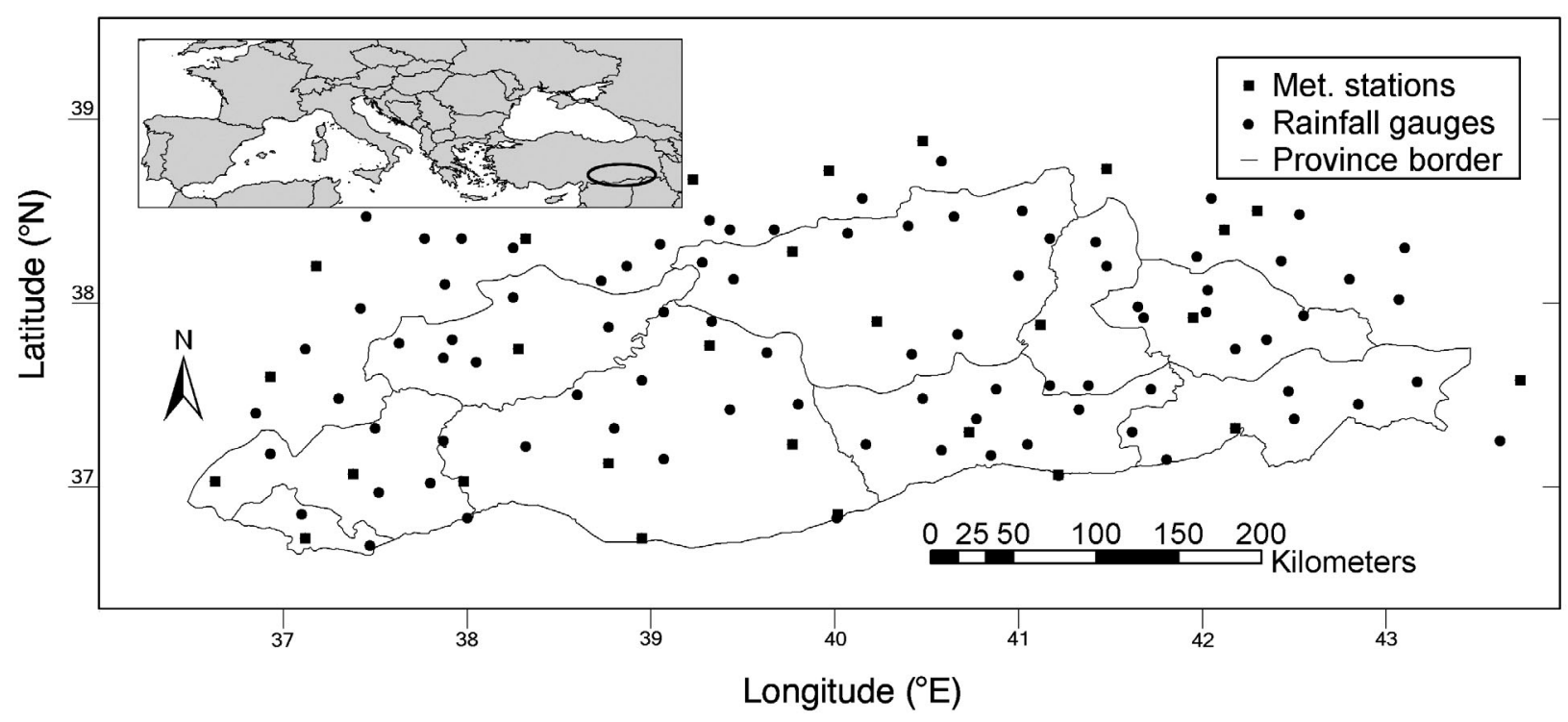

Fig. 1. Location of meteorological stations and rainfall gauges in the GAP region, Turkey

Although this is essentially used for estimation of areal rainfall, it has also been applied to the interpolation of point measurements (Goovaerts 2000).

The U.S. National Weather Service developed another method called 'inverse square distance' (see Bedient \& Huber 1992). In this method, the unknown rainfall quantity is estimated as a weighted average of surrounding values, the weights being reciprocal to the square distances from the unsampled location. Like the Thiessen polygon method, this technique does not permit consideration of factors such as topography. The isohyetal method (Chow 1964) was designed to overcome this deficiency by using the location and quantity for each gauge, as well as knowledge of the factors affecting these quantities, to interpolate lines of equal rainfall quantity (isohyets). This requires an extensive gauge network (Goovaerts 2000). Tabios \& Salas (1985) and Phillips et al. (1992) have demonstrated that geostatistical prediction techniques provide better estimates of rainfall than the above conventional methods. Interpolation techniques and mapping studies are summarized in Table 1.

Monthly mean climate surfaces were developed for the African continent by Hutchinson et al. (1996) and for Australia by Hutchinson \& Kesteven (1998). The gridded climate data were obtained by fitting thin plate smoothing spline functions of longitude, latitude and elevation to point values of climate variables. Some studies compared only geostatistical methods and identified one that gave the best result. Borga \& Vizzaccaro (1997) compared kriging and multiquadratic surface fitting for hydrologic variables; kriging performed better at lower gauge density, while at higher gauge density the accuracy of both estimators was similar. Goovaerts (2000) presented geostatistical approaches for incorporating elevation into the spatial interpolation of rainfall and found that ordinary kriging yielded more accurate predictions than other methods when the correlation between rainfall and elevation was moderate. Price et al. (2000) compared 2 methods - thin plate smoothing splines (ANUSPLIN) and a statistical method termed 'Gradient plus Inverse Distance Squared' (GIDS) - for elevation-dependent spatial interpolation of climatic data from sparse weather station networks. They used 30 yr monthly mean minimum and maximum temperatures and precipitation data from regions in western and eastern Canada and found that ANUSPLIN produced better results. Collins (1996) suggested the use of polynomial regression for temperature interpolation; ordinary kriging, surface under tension, and ordinary kriging with global climatological variogram have been recommended for rainfall interpolation by Atkinson \& Lloyd (1998), Saveliev et al. (1998), and Campling et al. (2001), respectively.

Some researchers found no significant differences between methods. Dirks et al. (1998) determined that results depended on the sampling density, and that for high-resolution networks the kriging method did not show greater predictive skill than simpler techniques such as the inverse square distance method. Michaud \& Sorooshian (1994) reported that kriging and multiquadratic interpolation gave similar results for $5 \mathrm{~min}$ convective rainfall.

Some studies have examined statistical relationships between geographical variables (orography, latitude and distance from sea) or landscape variables and 
climatological variables. Hevesi et al. (1992) reported a significant correlation between average annual precipitation and elevation recorded at 62 stations in Nevada and SE California. Ninyerola et al. (2000) developed a multiple regression analysis between temperature and rainfall as response variables, and some geographical variables (altitude, latitude, distance from the sea, solar radiation and a cloudiness factor) as predictor variables. Daly et al. (2000) introduced PRISM (a regression based model that uses point data) to develop $103 \mathrm{yr}$ (1895-1997) gridded monthly precipitation and maximum/minimum temperatures at $4 \mathrm{~km}$ resolution for the contiguous USA on the basis of approximately 8000 stations. Additionally, Daly et al. (2002) used PRISM, a digital elevation model (DEM), other spatial data sets, and human-expert parameterization to generate repeatable estimates of annual, monthly and event-based climatic elements. They prepared precipitation maps for the Olympic Mountains and temperature maps for coastal California.

\section{STUDY REGION}

The study was implemented in SE Turkey (Fig. 1), where GAP (a multi-sector integrated regional devel-

Table 1. Studies on spatial interpolation of climate variables; recommended methods are shown in bold. IDW: Inverse Distance Weighted, GPI: Global Polynomial Interpolation, LPI: Local Polynomial Interpolation, CRS: Completely Regularized Spline, KR: Kriging, KO: Ordinary Kriging, KS: Simple Kriging, KU: Universal Kriging, KD: Disjunctive Kriging, KI: Indicator Kriging, KT: Detrended Kriging CK: CoKriging, CKO: Ordinary CoKriging, CKS: Simple CoKriging, CKU: Universal CoKriging, CKD: Disjunctive CoKriging, TPSS: Thin Plate Smoothing Spline, GIDS: Gradient plus Inverse-Distance-Squared, TP: Thiessen Polygon, ISD: Inverse Square Distance

\begin{tabular}{|c|c|c|c|}
\hline Region & Variables $^{\mathrm{a}}$ & Interpolation methods & Source \\
\hline Switzerland & 1 & KO, KI & Atkinson \& Lloyd (1998) \\
\hline Northern Italy & 1 & $\mathbf{K R}$, multiquadratic surface fitting & Borga \& Vizzaccaro (1997) \\
\hline Southeastern Nigeria & 1 & $\begin{array}{l}\text { KO with global climatological variogram, } \\
\text { KO with phase variogram, KO with rain } \\
\text { depth variogram }\end{array}$ & Campling et al. (2001) \\
\hline Eastern and western North America & 5 & $\begin{array}{l}\text { IDW, optimal inverse distance, cubic } \\
\text { splining, polynomial regression, trend } \\
\text { surface analysis, lapse rate, KR, CK }\end{array}$ & Collins (1996) \\
\hline Norfolk Island & 1 & KR, IDW, TP, areal mean & Dirks et al. (1998) \\
\hline Pacific Northwest (USA) & 5 & $\begin{array}{l}\text { Neutral stability algorithm, linear lapse } \\
\text { rate adjustment }\end{array}$ & Dodson \& Marks (1997) \\
\hline Algarve region (Portugal) & 1 & $\begin{array}{l}\text { KS with varying local means, KR with an } \\
\text { external drift, colocated CK, TP, ISD, KO }\end{array}$ & Goovaerts (2000) \\
\hline Jalisco (Mexico) & 1,5 & IDW, TPSS, CK & Hartkamp et al. (1999) \\
\hline Australia & $1,3,5,7$ & TPSS & Hutchinson \& Kesteven (1998) \\
\hline Africa & 1,5 & TPSS & Hutchinson et al. (1996) \\
\hline Australia & $1,3,5,7,8$ & TPSS, KO & Jeffrey et al. (2001) \\
\hline Western Canada & 1,5 & $\begin{array}{l}\text { GIDS, KT, nearest neighbour, CK, ISD, } \\
\mathrm{KU}, \mathrm{KO}\end{array}$ & Nalder \& Wein (1998) \\
\hline Western Oregon & 1 & $\mathrm{KR}, \mathbf{K T}, \mathbf{C K}$ & Phillips et al. (1992) \\
\hline Western and eastern Canada & 1 & TPSS, GIDS & Price et al. (2000) \\
\hline Scotland & 1 & $\mathrm{KO}$, modified residual kriging & Prudhomme \& Reed (1999) \\
\hline Russia & 1 & Locally weighted polynomial regression & Rajagopalan \& Lall (1998) \\
\hline Switzerland & 1 & $\begin{array}{l}\text { Surface under tension, KR, zone kriging } \\
\text { with anisotropy semivariogram, zone } \\
\text { kriging with isotropy semivariogram }\end{array}$ & Saveliev et al. (1998) \\
\hline Central USA & 1 & $\begin{array}{l}\text { KU, optimal interpolation, } \mathrm{KO}, \mathrm{TP} \text {, inverse } \\
\text { square distance }\end{array}$ & Tabios \& Salas (1985) \\
\hline Northwestern USA & $1,2,3,5$ & Truncated Gaussian weighting filter & Thornton et al. (1997) \\
\hline GAP region (Turkey) & 1 to 6 & $\begin{array}{l}\text { IDW, GPI, LPI, CRS, KO, KS, KU, KD, CKO, } \\
\text { CKS, CKU, CKD }\end{array}$ & This study \\
\hline
\end{tabular}


opment project for sustainable development) is being implemented. GAP objectives include the improvement of living standards and incomes of the population to eliminate regional development disparities and contribute to social stability and economic growth by enhancing productivity and employment opportunities in the rural sector. The project area covers 9 administrative provinces (Adiyaman, Batman, Diyarbakir, Gaziantep, Kilis, Mardin, Siirt, Sanliurfa and Sirnak), bordering on Syria and Iraq. The GAP region has a surface area of $75358 \mathrm{~km}^{2}$ (9.7\% of the area of Turkey). Turkey has 8.5 million ha of irrigable land, of which almost $20 \%$ is located in the GAP region's wide plains in the basins of the lower Euphrates and Tigris rivers. Both rivers have their sources in eastern Anatolia and flow to the Persian Gulf. Since SE Anatolia receives less precipitation than the other regions of Turkey, it is planned to use the water of the Tigris and Euphrates for irrigation and energy generation by controlling the irregular flow regimes of both rivers (GAP Regional Development Administration website: www.gap.gov.tr).

The primary set of climate data for the GAP region includes solar radiation, sunshine duration, temperature, relative humidity, wind speed and rainfall, recorded from 1971 to 1999. All variables were measured at 27 meteorological stations, except for rainfall,which was determined at an additional 85 rainfall gauges (see Fig. 1).

The GAP area is located in the continental Mediterranean region, where annual precipitation is between 400 and $800 \mathrm{~mm}$ (see Table 2). This continental regime differs from the general Mediterranean regime in that it contributes more spring rain to the total precipitation (about 30 to $35 \%$ at most GAP stations; Komuscu et al. 1998, Turkes 1999). Besides the meteorological variables, we used digital elevation model (DEM) data from a $1 / 250000$ scale digital topographic map with a resolution of $0.01^{\circ}$ extending from $38^{\circ} 45^{\prime}$ to $36^{\circ} 30^{\prime} \mathrm{N}$ and from $36^{\circ} 30^{\prime}$ to $43^{\circ} 30^{\prime} \mathrm{E}$. The DEM data were required to consider elevation as a covariate for the cokriging methods.

\section{METHODS}

Interpolation techniques can be grouped into 2 main categories: deterministic and geostatistical. Deterministic interpolation techniques create surfaces from measured points, based on either the extent of similarity (e.g. IDW) or the degree of smoothing (e.g. CRS). A deterministic interpolation can either force the resulting surface to pass through the data values or not. An interpolation technique that predicts a value identical to the measured value at a sampled location is known as an exact interpolator. An inexact interpolator predicts a value that is different from the measured value and should be used to avoid sharp peaks or troughs in the output surface. IDW and CRS are exact interpolators, while GPI and LPI are inexact (Johnston et al. 2001).

Geostatistical interpolation techniques (e.g. kriging, cokriging) utilize the statistical properties of the measured points. Geostatistical techniques quantify the spatial autocorrelation among measured points and account for the spatial configuration of the sample points around the prediction location (Borga \& Vizzaccaro 1997, Campling et al. 2001, Johnston et al. 2001; for general descriptions see Isaaks \& Srivastava 1989, Cressie 1993, Rivoirard 1994, Kitanidis 1997, Chiles \& Delfiner 1999). The following deterministic and geostatistical methods were used in the study.

4.1. Inverse distance weighted. IDW interpolation explicitly implements the assumption that objects that are close to one another are more alike than those that are farther apart. Thus, IDW assumes that each measured point has a local influence that diminishes with distance. To predict a value for any unmeasured loca-

Table 2. Long-term averages of annual climatic elements typical for the provinces in the GAP region

\begin{tabular}{|c|c|c|c|c|c|c|c|c|}
\hline Stn & $\begin{array}{l}\text { Latitude } \\
\text { (N) }\end{array}$ & $\begin{array}{l}\text { Longitude } \\
\text { (E) }\end{array}$ & 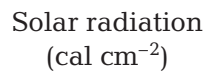 & $\begin{array}{c}\text { Sunshine } \\
\text { duration (h) }\end{array}$ & $\begin{array}{c}\text { Temperature } \\
\left({ }^{\circ} \mathrm{C}\right)\end{array}$ & $\begin{array}{c}\text { Relative } \\
\text { humidity (\%) }\end{array}$ & $\begin{array}{c}\text { Wind } \\
\text { speed }\left(\mathrm{m} \mathrm{s}^{-1}\right)\end{array}$ & $\begin{array}{c}\text { Rainfall } \\
(\mathrm{mm})\end{array}$ \\
\hline Adiyaman & $37.75^{\circ}$ & $38.28^{\circ}$ & 311.2 & 8.0 & 17.0 & 51.5 & 0.2 & 688 \\
\hline Batman & $37.88^{\circ}$ & $41.12^{\circ}$ & 306.0 & 7.5 & 16.6 & 58.2 & 1.0 & 473 \\
\hline Diyarbakir & $37.90^{\circ}$ & $40.23^{\circ}$ & 405.5 & 7.8 & 15.5 & 56.9 & 2.6 & 474 \\
\hline Elazig & $38.67^{\circ}$ & $39.23^{\circ}$ & 355.0 & 7.4 & 12.9 & 54.9 & 2.2 & 413 \\
\hline Gaziantep & $37.07^{\circ}$ & $37.38^{\circ}$ & 348.9 & 7.0 & 14.8 & 61.4 & 1.3 & 545 \\
\hline Hakkari & $37.58^{\circ}$ & $43.73^{\circ}$ & 374.5 & 7.8 & 10.2 & 55.1 & 1.6 & 733 \\
\hline Kilis & $36.72^{\circ}$ & $37.12^{\circ}$ & 407.3 & 7.8 & 16.8 & 54.8 & 2.5 & 494 \\
\hline Mardin & $37.30^{\circ}$ & $40.73^{\circ}$ & - & 8.2 & 15.9 & 48.7 & 4.0 & 689 \\
\hline Mus & $38.73^{\circ}$ & $41.48^{\circ}$ & 356.0 & 7.2 & 10.0 & 62.3 & 1.3 & 757 \\
\hline Siirt & $37.92^{\circ}$ & $41.95^{\circ}$ & 377.2 & 7.6 & 15.8 & 51.5 & 1.5 & 692 \\
\hline Sanliurfa & $37.13^{\circ}$ & $38.77^{\circ}$ & 385.5 & 7.9 & 18.2 & 52.7 & 1.5 & 455 \\
\hline
\end{tabular}


tion, IDW will use the measured values surrounding the prediction location. Those measured values closest to the prediction location will have the greatest influence on the predicted value (Ashraf et al. 1997, Nalder \& Wein 1998, Johnston et al. 2001).

4.2. Global polynomial interpolation. GPI fits a smooth surface that is defined by a mathematical function to the input sample points. The GPI surface changes gradually and captures coarse-scale pattern in the data. It creates a slowly varying surface using low-order polynomials that possibly describe some physical process. However, the more complex the polynomial, the more difficult it is to ascribe physical meaning to it. Furthermore, the calculated surfaces are highly susceptible to outliers (extremely high and low values), especially at the edges (Johnston et al. 2001). A first-order globyl polynomial (GP) fits a single plane through the data; a second-order GP fits a surface with a bend in it, allowing the calculation of surfaces representing valleys; a third-order GP allows for 2 bends; and so forth. However, when a surface has a different shape, as in a landscape that slopes, levels out, and then slopes again, a single GP will not fit well (Johnston et al. 2001).

4.3. Local polynomial interpolation. While GPI fits a polynomial to the entire surface, LPI fits many polynomials, each within specified overlapping neighborhoods. The search neighborhood can be defined using the search neighborhood dialog. The shape, maximum and minimum number of points, and the sector configuration can be specified. Alternatively, a slider can be used to define the width of the neighborhood in conjunction with a power parameter that will, based on distance, decrease the weights of the sample points within the neighborhood. Thus, LPI produces surfaces that account for more local variation (Rajagopalan \& Lall 1998, Johnston et al. 2001).

4.4. Completely regularized spline. Radial basic function (RBF) methods such as CRS are exact interpolation techniques; the surface is forced through each measured sample value. RBFs include thin-plate spline, spline with tension, CRS, multiquadric function, and inverse multiquadric function. Each function has a different shape and results in a slightly different interpolation surface. RBF methods are a form of artificial neural network.

RBFs are conceptually similar to fitting a rubber membrane through the measured sample values while minimizing the total curvature of the surface. The selected basic function determines how the rubber membrane will fit between the values.

As opposed to IDW, RBF methods can predict values above the maximum and below the minimum measured values. RBFs are used for calculating smooth surfaces from a large number of data points. The functions produce good results for gently varying surfaces such as elevation. The techniques are inappropriate when there are large changes in the surface values within a short horizontal distance and/or when the sample data are prone to error or uncertainty (Johnston et al. 2001).

4.5. Kriging. Over the past several decades kriging has become a fundamental tool in geostatistics (Caruso \& Quarta 1998). Kriging forms weights from surrounding measured values to predict values at unmeasured locations. As with IDW interpolation, the closest measured values usually have the most influence, but kriging weights are more sophisticated. IDW uses a simple algorithm based on distance, whereas kriging weights come from a semivariogram developed from the spatial structure of the data. To create a continuous surface or map of the phenomenon, predictions are made for locations in the study area based on the semivariogram and the spatial arrangement of nearby measured values (Collins 1996, Johnston et al. 2001). Four different kriging types were used in this study.

4.5.1. Ordinary kriging $(\boldsymbol{K O})$ : This is the most general and widely used of the kriging methods. It estimates the value of the climatic variable at a given point from the values at surrounding stations and from a variogram model for that variable (Nalder \& Wein 1998, Johnston et al. 2001).

4.5.2. Simple kriging (KS): This uses the average of the entire data set (while ordinary kriging uses a local average, i.e. the average of the scatter points in the kriging subset for a particular interpolation point). As a result, KS may be less accurate than ordinary kriging, but it generally produces a result that is smoother.

4.5.3. Universal kriging $(\boldsymbol{K U})$ : This assumes that there is an overriding trend in the data which can be modeled by a deterministic function, i.e. by a polynomial. This polynomial is subtracted from the original measured points, and the autocorrelation is modeled from the random errors. Once the model is fit to the random errors, before making a prediction, the polynomial is added back to the predictions to give meaningful results (Nalder \& Wein 1998, Johnston et al. 2001).

4.5.4. Disjunctive kriging $(\boldsymbol{K D})$ : This requires the assumption of bivariate normality. This assumption is difficult to verify, and the solutions are mathematically and computationally complicated. KD can use either semivariograms or covariances, and it can use transformations, but it cannot allow for measurement error (Johnston et al. 2001).

4.6. Cokriging. Cokriging is similar to kriging, except that it uses additional covariates, e.g. the climatic variable and elevation. In other words cokriging uses the advantages of inter-variable correlation. Cokriging is most effective when the covariates are highly correlated (Collins 1996, Ashraf et al. 1997, Nalder \& Wein 1998). Four different cokriging types similar to 
the kriging types were used in this study: ordinary $(\mathrm{CKO})$; simple (CKS); universal (CKU); and disjunctive (CKD).

4.7. Cross validation. Cross validation is used to compare measured values with interpolated values using only the information available in the sample data set. A cross validation study can help to choose between different weighting procedures, between different search strategies, or between different estimation methods. The sample value at a particular location is temporarily discarded from the sample data set; the value at the same location is then estimated using the remaining samples. Once the estimate is calculated, the calculated value can be compared with the true value that was initially removed from the sample data set. This procedure is repeated for all available sample values (Isaaks \& Srivastava 1989). In this study all parameters of methods were optimized for minimum cross validation error.

4.8. Comparison. Errors were calculated as 'actual minus predicted' and the mean of these errors was calculated in 4 ways: mean error (ME), indicating the degree of bias; mean absolute error (MAE), providing a measure of how far the estimate can be in error, ignoring its sign; mean relative error (MRE), providing a measure of how far the estimate can be in error relative to the measured mean; root mean square error (RMSE), providing a measure that is sensitive to outliers.

\section{RESULTS AND DISCUSSION}

Yearly prediction maps were generated for each meteorological variable with the 12 interpolation methods. Long-term yearly mean temperature maps are given in Fig. 2 as an example. Detailed statistics of the measured and calculated data from 1971 to 1999 are given in Table 3. In earlier studies, generally MAE, MRE and RMSE were used to determine which method was the best, and we considered MAE and RMSE.

5.1. Inverse distance weighted. IDW performed poorly for all climate variables. It had no lowest MAE and RMSE value, but it had 2 maximum MAE and RMSE values (solar radiation and wind speed). IDW results were implausible when data were sparse. Among 19 previous studies (Table 1) IDW was recommended only by Dirks et al. (1998) for rainfall interpolation. The one advantage of IDW was that it consistently adhered to the measured range of the data, as mentioned by Johnston et al. (2001). The pattern of IDW was very changeable depending on the point data (Fig. 2a).

5.2. Global polynomial interpolation. GPI produced the poorest results. It had no lowest, and 8 of the 12 highest MAE and RMSE values. The GPI method may be suitable for slowly varying surfaces, but in the GAP region there were significant changes from point to point in all climate variables. The pattern of GPI consisted of almost straight lines and variability was small (Fig. 2b).

5.3. Local polynomial interpolation. LPI produced poor results. Since the LPI method defined smaller regions with many polynomials, rather than whole region, its error values were equal to or smaller than those for GPI. Consequently, LPI cannot be recommended for the GAP region. LPI created a pattern similar to GPI, but its variability was greater (Fig. 2c).

5.4. Completely regularized spline. Of the methods which do not use elevation as ancillary information, CRS was the most plausible from a visual standpoint. CRS had minimum MAE and RMSE values in rainfall and minimum RMSE in sunshine duration. The CRS method did not have the highest error value for any climate parameter. CRS gave the best result for a large number of data points and varying surfaces, and this was exemplified by the rainfall data. If useable elevation values are lacking, CRS may be used in climate interpolation in the GAP region. CRS created 2 high temperature centers, with significant temperature decreases around them (Fig. 2d).

5.5. Kriging. Only KS and KD had minimum MAE and RMSE values, in the case of wind speed. The KO and KU methods did not produce any minimum MAE and RMSE values. Subtypes of kriging generally gave similar results, especially KO and KU.

Tabios \& Salas (1985) found that KU gave lower MAE than KO for annual precipitation in the central USA, but in this study on the GAP region they produced the same MAE values. Goovaerts (2000) found that $\mathrm{KO}$ produced the most accurate rainfall values. In this study KO gave the second lowest MAE value for rainfall. While the patterns of $\mathrm{KO}$ and $\mathrm{KU}$ were similar to those of the LPI method, the patterns of KS and KD were similar to CRS (Fig. 2e-h).

5.6. Cokriging. The inclusion of elevation as a covariate reduced the error, as expected. This applies especially to temperature and solar radiation.

CKS produced the lowest MAE values in temperature, sunshine duration, solar radiation, relative humidity and the lowest RMSE values in temperature, solar radiation, relative humidity and wind speed. Although cokriging was used in 5 of the 19 previous studies, only Philips et al. (2000) suggested it for rainfall interpolation (Table 1). CKD had minimum MAE values (equal to CKS) in relative humidity and wind speed. The other 2 cokriging subtypes (CKO and CKU) had no minimum or maximum error values. They produced almost the same error values as the kriging method. 

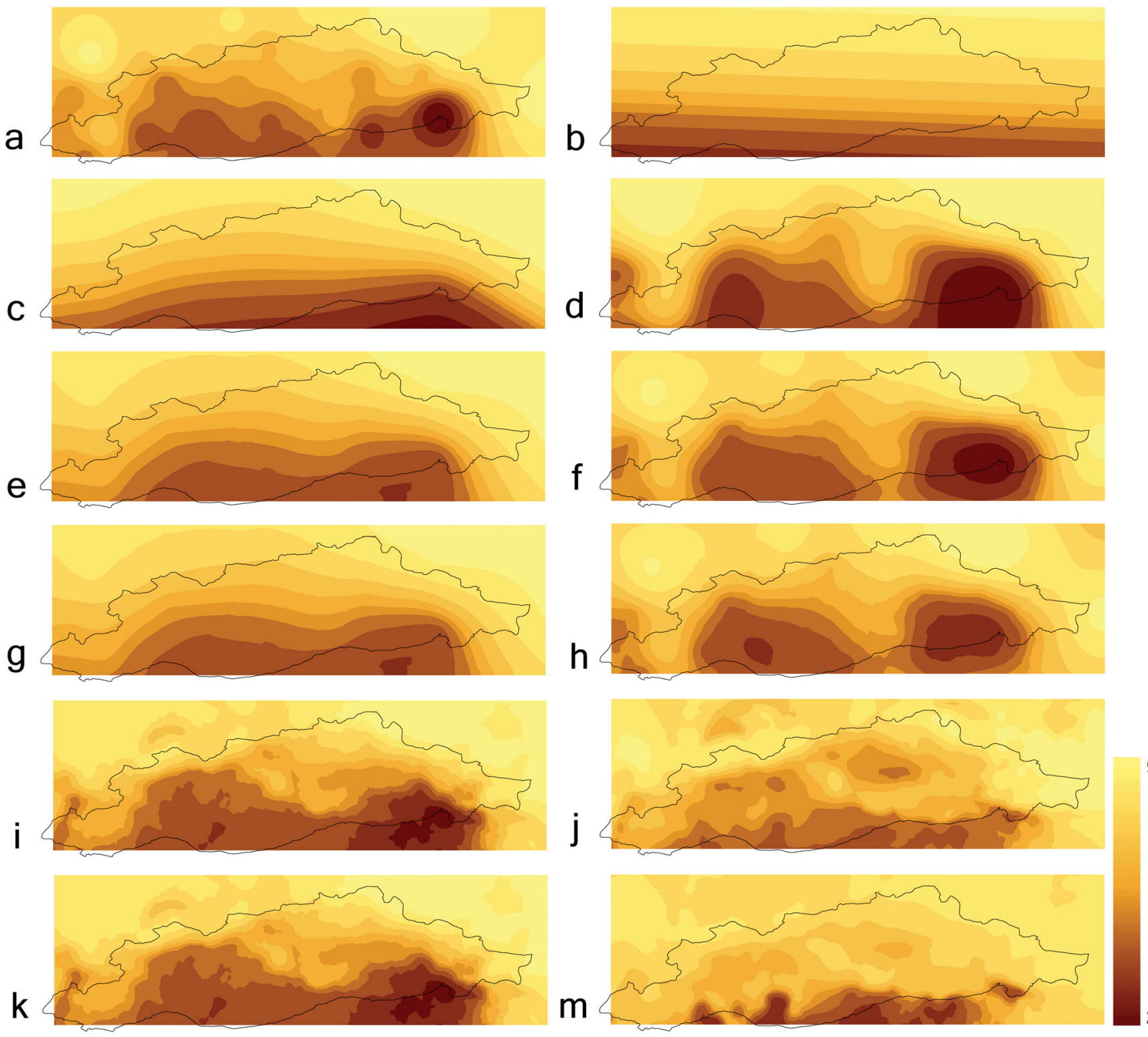

Fig. 2. Long-term yearly predicted temperature in the GAP region of Turkey. (a) Inverse Distance Weighted, (b) Global Polynomial Interpolation, (c) Local Polynomial Interpolation, (d) Completely Regularized Spline, (e) Ordinary Kriging, (f) Simple Kriging, (g) Universal Kriging, (h) Disjunctive Kriging, (i) Ordinary CoKriging, (j) Simple CoKriging, (k) Universal CoKriging, (m) Disjunctive CoKriging

The patterns produced by CKO and CKU were almost identical. Since interpolation of point data was dependent on the elevation, distribution was very variable from point to point. CKS and CKD also created very changeable distributions, but they led to colder results than the others (Fig. $2 \mathrm{i}-\mathrm{m}$ ).

5.7. Effect of elevation on climate interpolation. The analysis showed that when information is available on the elevation of the stations (DEM), then CKS should be used to produce the climate surface. In the absence of this information, KD or CRS may be used. Kriging and cokriging estimation errors were compared to show the effect of elevation on interpolation. For temperature estimates, all cokriging error values (i.e. MAE and RMSE values for CKO, CKS, CKU and CKD) were smaller than those for the kriging method. This was similar for solar radiation values, but to a lesser extent. There was no significant correlation between elevation and sunshine duration, relative humidity, and rainfall, when comparing the kriging and cokriging methods. Error values for wind speed were almost identical in both kriging and cokriging analyses. 
Table 3. Summary statistics for the interpolation of observed climate data (1971-1999). CV: coefficient of variation; ME: mean error; MAE: mean absolute error; MRE: mean relative error; RMSE: root mean square error; $\mathrm{N}=$ number of data. Model abbreviations as in Table 1. Lowest MAE, MRE and RMSE values are in bold and highest values are underlined

\begin{tabular}{|c|c|c|c|c|c|c|c|c|c|c|}
\hline & Mean & $\mathrm{SD}$ & $\mathrm{CV}$ & Min. & Median & Max. & $\mathrm{ME}$ & MAE & MRE & RMSE \\
\hline \multicolumn{11}{|c|}{ Temperature $\left({ }^{\circ} \mathrm{C}\right) ; \mathrm{N}=643$} \\
\hline Measured & 14.50 & 3.22 & 0.22 & 2.1 & 15.2 & 20.8 & & & & \\
\hline IDW & 14.52 & 2.14 & 0.15 & 8.4 & 15.0 & 18.8 & 0.02 & 1.81 & 12.48 & 2.33 \\
\hline GPI & 14.55 & 2.56 & 0.18 & 7.8 & 14.6 & 20.1 & 0.06 & $\underline{1.91}$ & $\underline{13.17}$ & $\underline{2.43}$ \\
\hline LPI & 14.37 & 2.66 & 0.18 & 6.8 & 14.6 & 20.1 & -0.13 & $\overline{1.52}$ & $\overline{10.48}$ & $\overline{2.06}$ \\
\hline CRS & 14.60 & 2.55 & 0.17 & 7.0 & 15.0 & 19.2 & 0.11 & 1.54 & 10.62 & 2.07 \\
\hline $\mathrm{KO}$ & 14.57 & 2.21 & 0.15 & 7.6 & 14.9 & 18.8 & 0.08 & 1.67 & 11.52 & 2.18 \\
\hline KS & 14.57 & 2.12 & 0.15 & 7.9 & 15.0 & 19.2 & 0.07 & 1.81 & 12.48 & 2.24 \\
\hline KU & 14.58 & 2.19 & 0.15 & 7.6 & 14.9 & 18.8 & 0.08 & 1.67 & 11.52 & 2.18 \\
\hline $\mathrm{KD}$ & 14.54 & 2.13 & 0.15 & 8.1 & 15.0 & 19.2 & 0.04 & 1.83 & 12.62 & 2.26 \\
\hline $\mathrm{CKO}$ & 14.87 & 2.32 & 0.16 & 8.0 & 15.3 & 19.5 & 0.37 & 1.54 & 10.62 & 1.99 \\
\hline CKS & 14.24 & 2.46 & 0.17 & 5.9 & 14.9 & 18.4 & -0.25 & 1.45 & 10.00 & 1.82 \\
\hline CKU & 14.86 & 2.34 & 0.16 & 8.0 & 15.3 & 19.5 & 0.37 & 1.54 & 10.62 & 1.99 \\
\hline CKD & 14.13 & 2.05 & 0.15 & 8.5 & 14.2 & 20.6 & -0.36 & 1.79 & 12.34 & 2.16 \\
\hline \multicolumn{11}{|c|}{ Sunshine duration (h); N = 419} \\
\hline Measured & 7.44 & 0.77 & 0.10 & 2.8 & 7.5 & 9.1 & & & & \\
\hline IDW & 7.37 & 0.49 & 0.07 & 5.5 & 7.5 & 8.5 & -0.06 & 0.50 & 6.72 & 0.67 \\
\hline GPI & 7.45 & 0.48 & 0.06 & 6.2 & 7.4 & 9.2 & 0.01 & $\underline{0.54}$ & $\underline{7.26}$ & $\underline{0.73}$ \\
\hline LPI & 7.38 & 0.49 & 0.07 & 6.0 & 7.4 & 8.6 & -0.06 & 0.47 & 6.32 & 0.64 \\
\hline CRS & 7.40 & 0.56 & 0.07 & 4.6 & 7.5 & 9.5 & -0.03 & 0.46 & 6.18 & 0.60 \\
\hline $\mathrm{KO}$ & 7.44 & 0.39 & 0.05 & 6.5 & 7.4 & 8.5 & 0.00 & 0.51 & 6.85 & 0.70 \\
\hline KS & 7.38 & 0.39 & 0.05 & 5.8 & 7.4 & 8.4 & -0.06 & 0.47 & 6.32 & 0.62 \\
\hline KU & 7.44 & 0.39 & 0.05 & 6.5 & 7.4 & 8.5 & 0.00 & 0.51 & 6.85 & 0.70 \\
\hline $\mathrm{KD}$ & 7.42 & 0.40 & 0.05 & 6.2 & 7.5 & 8.3 & -0.01 & 0.48 & 6.45 & 0.63 \\
\hline CKO & 7.45 & 0.38 & 0.05 & 6.5 & 7.5 & 8.4 & 0.02 & 0.51 & 6.85 & 0.70 \\
\hline CKS & 7.40 & 0.39 & 0.05 & 6.4 & 7.4 & 8.4 & -0.04 & 0.45 & 6.05 & 0.62 \\
\hline CKU & 7.45 & 0.38 & 0.05 & 6.5 & 7.5 & 8.4 & 0.02 & 0.51 & 6.85 & 0.70 \\
\hline CKD & 7.41 & 0.35 & 0.05 & 6.6 & 7.4 & 8.6 & -0.02 & 0.47 & 6.32 & 0.65 \\
\hline \multicolumn{11}{|c|}{ Solar radiation $\left(\mathrm{cal} \mathrm{cm}^{-2}\right) ; \mathrm{N}=312$} \\
\hline Measured & 364.87 & 43.07 & 0.12 & 182.3 & 368.9 & 460.4 & & & & \\
\hline IDW & 364.46 & 21.47 & 0.06 & 230.1 & 365.0 & 420.7 & -0.43 & $\underline{34.83}$ & $\underline{9.55}$ & $\underline{46.39}$ \\
\hline GPI & 364.81 & 20.77 & 0.06 & 291.9 & 364.9 & 458.4 & -0.08 & 34.56 & 9.47 & 45.00 \\
\hline LPI & 364.37 & 21.59 & 0.06 & 284.6 & 363.6 & 464.6 & -0.51 & 33.51 & 9.18 & 43.83 \\
\hline CRS & 364.67 & 20.24 & 0.06 & 271.7 & 364.8 & 422.3 & -0.20 & 34.07 & 9.34 & 45.33 \\
\hline $\mathrm{KO}$ & 363.34 & 20.91 & 0.06 & 304.4 & 360.4 & 418.6 & -1.64 & 34.74 & 9.52 & 45.48 \\
\hline KS & 364.94 & 12.41 & 0.03 & 332.2 & 367.8 & 392.1 & 0.04 & 30.37 & 8.32 & 40.52 \\
\hline KU & 363.34 & 20.91 & 0.06 & 304.4 & 360.4 & 418.6 & -1.64 & 34.74 & 9.52 & 45.48 \\
\hline $\mathrm{KD}$ & 367.22 & 12.90 & 0.04 & 335.5 & 369.5 & 403.7 & 2.21 & 30.01 & 8.22 & 40.62 \\
\hline CKO & 365.12 & 18.09 & 0.05 & 306.3 & 365.4 & 416.9 & 0.21 & 32.94 & 9.03 & 44.01 \\
\hline CKS & 363.13 & 15.89 & 0.04 & 315.0 & 362.6 & 398.3 & -1.74 & 29.54 & 8.10 & 39.30 \\
\hline CKU & 365.12 & 18.09 & 0.05 & 306.3 & 365.4 & 416.9 & 0.21 & 32.94 & 9.03 & 44.01 \\
\hline CKD & 363.68 & 13.10 & 0.04 & 331.2 & 362.3 & 396.7 & -1.26 & 29.64 & 8.12 & 39.72 \\
\hline \multicolumn{11}{|c|}{ Relative humidity (\%); N = 643} \\
\hline Measured & 56.70 & 6.36 & 0.11 & 40.2 & 56.3 & 77.0 & & & & \\
\hline IDW & 56.90 & 4.02 & 0.07 & 47.3 & 56.4 & 75.1 & 0.20 & 4.52 & 7.97 & 5.76 \\
\hline GPI & 56.72 & 3.64 & 0.06 & 47.8 & 56.7 & 81.3 & 0.02 & $\underline{5.24}$ & $\underline{9.24}$ & $\underline{6.65}$ \\
\hline LPI & 57.00 & 4.17 & 0.07 & 45.4 & 56.9 & 73.0 & 0.30 & 4.41 & 7.78 & 5.58 \\
\hline CRS & 56.69 & 3.85 & 0.07 & 47.1 & 56.4 & 69.4 & -0.01 & 4.37 & 7.71 & 5.58 \\
\hline $\mathrm{KO}$ & 56.68 & 3.34 & 0.06 & 48.2 & 56.6 & 68.0 & -0.02 & 4.47 & 7.88 & 5.73 \\
\hline KS & 56.80 & 3.16 & 0.06 & 46.5 & 57.0 & 72.1 & 0.10 & 4.30 & 7.58 & 5.42 \\
\hline KU & 56.69 & 3.34 & 0.06 & 48.2 & 56.6 & 68.0 & -0.01 & 4.46 & 7.87 & 5.73 \\
\hline $\mathrm{KD}$ & 56.72 & 2.96 & 0.05 & 48.7 & 56.9 & 67.2 & 0.02 & 4.29 & 7.57 & 5.39 \\
\hline CKO & 56.55 & 3.17 & 0.06 & 48.4 & 56.6 & 69.5 & -0.14 & 4.57 & 8.06 & 5.85 \\
\hline CKS & 56.92 & 3.47 & 0.06 & 46.5 & 57.1 & 70.0 & 0.21 & 4.24 & 7.48 & 5.31 \\
\hline CKU & 56.55 & 3.17 & 0.06 & 48.4 & 56.6 & 69.5 & -0.14 & 4.57 & 8.06 & 5.85 \\
\hline CKD & 56.75 & 2.98 & 0.05 & 49.0 & 57.1 & 65.4 & 0.05 & 4.24 & 7.48 & 5.35 \\
\hline
\end{tabular}


Table 3. (continued)

\begin{tabular}{|c|c|c|c|c|c|c|c|c|c|c|}
\hline & Mean & $\mathrm{SD}$ & $\mathrm{CV}$ & Min. & Median & Max. & ME & MAE & MRE & RMSE \\
\hline \multicolumn{11}{|c|}{ Wind speed $\left(\mathrm{m} \mathrm{s}^{-1}\right) ; \mathrm{N}=462$} \\
\hline Measured & 1.78 & 0.79 & 0.45 & 0.1 & 1.6 & 6.9 & & & & \\
\hline IDW & 1.75 & 0.39 & 0.22 & 0.9 & 1.7 & 3.2 & -0.03 & $\underline{0.65}$ & 36.52 & $\underline{0.86}$ \\
\hline GPI & 1.71 & 0.25 & 0.15 & 1.0 & 1.7 & 3.3 & -0.07 & 0.64 & 35.96 & 0.85 \\
\hline LPI & 1.72 & 0.37 & 0.22 & 0.6 & 1.7 & 4.1 & -0.06 & 0.64 & 35.96 & 0.85 \\
\hline CRS & 1.73 & 0.37 & 0.22 & 0.8 & 1.7 & 4.1 & -0.05 & 0.62 & 34.83 & 0.84 \\
\hline $\mathrm{KO}$ & 1.70 & 0.39 & 0.23 & 0.6 & 1.7 & 4.2 & -0.09 & 0.63 & 35.39 & 0.84 \\
\hline KS & 1.71 & 0.21 & 0.12 & 0.9 & 1.7 & 3.4 & -0.07 & 0.56 & 31.46 & 0.77 \\
\hline KU & 1.70 & 0.39 & 0.23 & 0.6 & 1.7 & 4.2 & -0.09 & 0.63 & 35.39 & 0.84 \\
\hline $\mathrm{KD}$ & 1.67 & 0.17 & 0.10 & 1.0 & 1.6 & 2.4 & -0.11 & 0.56 & 31.46 & 0.78 \\
\hline CKO & 1.70 & 0.22 & 0.13 & 1.1 & 1.7 & 2.7 & -0.08 & 0.61 & 34.27 & 0.84 \\
\hline CKS & 1.71 & 0.18 & 0.11 & 1.2 & 1.7 & 2.9 & -0.08 & 0.56 & 31.46 & 0.77 \\
\hline CKU & 1.70 & 0.22 & 0.13 & 1.1 & 1.7 & 2.7 & -0.08 & 0.61 & 34.27 & 0.84 \\
\hline CKD & 1.66 & 0.16 & 0.10 & 1.1 & 1.7 & 2.4 & -0.12 & 0.56 & 31.46 & 0.78 \\
\hline \multicolumn{11}{|c|}{ Rainfall (mm); N = 1414} \\
\hline Measured & 635.55 & 265.96 & 0.42 & 104.7 & 600.9 & 1899.0 & & & & \\
\hline IDW & 659.16 & 188.77 & 0.29 & 281.5 & 642.6 & 1684.7 & 23.61 & 153.45 & 24.14 & 199.83 \\
\hline GPI & 635.60 & 167.89 & 0.26 & 150.2 & 634.3 & 1079.9 & 0.05 & 170.56 & $\underline{26.84}$ & $\underline{221.61}$ \\
\hline LPI & 640.98 & 197.06 & 0.31 & 85.7 & 627.5 & 1316.8 & 5.43 & 151.10 & 23.77 & 200.54 \\
\hline CRS & 645.69 & 200.97 & 0.31 & 237.2 & 633.8 & 1608.5 & 10.14 & 141.33 & 22.24 & 185.94 \\
\hline $\mathrm{KO}$ & 639.97 & 177.34 & 0.28 & 244.6 & 627.2 & 1230.8 & 4.42 & 151.03 & 23.76 & 198.19 \\
\hline KS & 648.49 & 173.87 & 0.27 & 253.9 & 629.9 & 1543.8 & 12.93 & 151.89 & 23.90 & 195.15 \\
\hline KU & 639.97 & 177.34 & 0.28 & 244.6 & 627.2 & 1230.8 & 4.42 & 151.03 & 23.76 & 198.19 \\
\hline $\mathrm{KD}$ & 641.84 & 165.59 & 0.26 & 232.4 & 627.5 & 1312.3 & 6.28 & 151.17 & 23.79 & 195.73 \\
\hline $\mathrm{CKO}$ & 633.48 & 170.14 & 0.27 & 219.0 & 623.3 & 1263.0 & -2.07 & 151.31 & 23.81 & 198.29 \\
\hline CKS & 655.60 & 165.63 & 0.25 & 285.1 & 643.0 & 1210.4 & 20.05 & 152.91 & 24.06 & 195.65 \\
\hline CKU & 633.48 & 170.14 & 0.27 & 219.0 & 623.3 & 1263.0 & -2.07 & 151.31 & 23.81 & 198.29 \\
\hline CKD & 653.77 & 159.82 & 0.24 & 243.5 & 644.3 & 1116.9 & 18.28 & 154.59 & 24.32 & 199.29 \\
\hline
\end{tabular}

5.8. Effect of variance and range on climate interpolation. MRE increased with increasing coefficient of variation $(\mathrm{CV})$ and range of values. Wind speed had the highest MRE, and $C V$ and range (Table 3, 'Measured'). Similarly, among variables the rank of $\mathrm{CV}$ values was the same as the rank of MRE (sunshine duration had the lowest, and wind speed the highest).

\section{CONCLUSIONS}

This study aimed to determine the best method (lowest cross validation error) for interpolating the spatial distribution of 6 different climate parameters (solar radiation, sunshine duration, temperature, relative humidity, wind speed and rainfall) in the GAP region of Turkey for 1971 to 1999. Based on the MAE and RMSE values of the predictions, CKD or CRS interpolation should be used when DEM data are not available. CRS was especially successful for rainfall interpolation. When DEM data are available, then CKS should be used for interpolation of temperature, solar radiation, relative humidity, and wind speed.
Interpolation of temperature and solar radiation with consideration of elevation data brought about better results.

The agricultural and environmental importance of the GAP region of Turkey will increase with the current regional development effort. Interpolation techniques make it possible to predict climate-dependent parameters for watershed management, crop growth modeling, and soil-plant-water interaction studies, although temporal and spatial measurements of meteorological parameters are not yet adequate in the region.

Acknowledgements. The authors acknowledge the assistance of I. Cakmak for data processing and I. Bayramin, G. Erpul and Z. Gokalp for valuable comments.

\section{LITERATURE CITED}

Ashraf M, Loftis JC, Hubbard KG (1997) Application of geostatistics to evaluate partial weather station networks. Agric For Meteorol 84:255-271

Atkinson PM, Lloyd CD (1998) Mapping precipitation in Switzerland with ordinary and indicator kriging. J Geogr Inf Decision Anal 2(2):65-76 
Bedient PB, Huber WC (1992) Hydrology and floodplain analysis, 2nd edn. Addison-Wesley, Reading, MA

Borga M, Vizzaccaro A (1997) On the interpolation of hydrologic variables: formal equivalence of multiquadratic surface fitting and kriging. J Hydrol 195:160-171

Campling P, Gobin A, Feyen J (2001) Temporal and spatial rainfall analysis across a humid tropical catchment. Hydrol Process 15:359-375

Caruso C, Quarta F (1998) Interpolation methods comparison. Comput Math Applic 35(12):109-126

Chiles J, Delfiner P (1999) Geostatistics. Modeling spatial uncertainty. John Wiley \& Sons, New York

Chow VT (1964) Handbook of hydrology. McGraw-Hill, New York

Collins FC (1996) A comparison of spatial interpolation techniques in temperature estimation. Third Int Conf Workshop on Integrating GIS and Environmental Modeling. January 21-25, 1996, Santa Fe, NM

Cressie N (1993) Statistics for spatial data. John Wiley \& Sons, New York

Daly C, Kittel TGF, McNab A, Gibson WP and 5 others (2000) Development of a 103-year high-resolution climate data set for the conterminous United States. In: Proc 12th American Meteorological Society Conf on Applied Climatology, p 249-252, Asheville, NC

Daly C, Gibson WP, Taylor GH, Johnson GL, Pasteris P (2002) A knowledge-based approach to the statistical mapping of climate. Clim Res 22:99-113

Dirks KN, Hay JE, Stow, CD, Harris D (1998) High-resolution studies of rainfall on Norfolk Island. Part II: Interpolation of rainfall data. J Hydrol 208(3-4):187-193

Dodson R, Marks D (1997) Daily air temperature interpolated at high spatial resolution over a large mountainous region. Clim Res 8:1-20

Goovaerts P (2000) Geostatistical approaches for incorporating elevation into the spatial interpolation of rainfall. J Hydrol 228:113-129

Hartkamp AD, Beurs KD, Stein A, White JW (1999) Interpolation techniques for climate variables. NRG-GIS Series 99-01. International Maize and Wheat Improvement Center (CIMMYT) Mexico City

Hevesi JA, Istok JD, Flint AL (1992) Precipitation estimation in mountainous terrain using multivariate geostatistics. Part I: Structural analysis. J Appl Meteorol 31:661-676

Hutchinson MF, Kesteven JL (1998) Monthly mean climate surfaces for Australia, undertaken in CRES. Available at: http://cres.anu.edu.au/outputs/climatesurfaces/index.php

Hutchinson MF, Nix HA, McMahon JP, Ord KD (1996) The development of a topographic and climate database for Africa. Third Int Conf Workshop on Integrating GIS and Environmental Modeling. January 21-25, 1996, Santa Fe, NM

Isaaks EH, Srivastava RM (1989) An introduction to ap-

Editorial responsibility: Otto Kinne,

Oldendorf/Luhe, Germany plied geostatistics. Oxford Univesity Press, New York Jeffrey SJ, Carter JO, Moodie KB, Beswick AR (2001) Using spatial interpolation to construct a comprehensive archive of Australian climate data. Environ Model Software 16: 309-330

Johnston K, Ver Hoef JM, Krivoruchko K, Lucas N (2001) Using ArcGIS Geostatistical Analyst. ESRI, Redlands, CA

Kitanidis PK (1997) Introduction to geostatistics: applications in hydrogeology. Cambridge University Press, Cambridge

Komuscu AU, Erkan A, Oz S (1998) Possible impacts of climate change on soil moisture availability in the Southeast Anatolia Development Project Region (GAP): an analysis from an agricultural drought perspective. Clim Change 40:519-545

Michaud JD, Sorooshian S (1994) Effect of rainfall-sampling errors on simulations of desert flash floods. Water Resour Res 30(10):2765-2775

Nalder IA, Wein RW (1998) Spatial interpolation of climatic normals: test of a new method in the Canadian boreal forest. Agric For Meteorol 92:211-225

Ninyerola M, Pons X, Roure JM (2000) A methodological approach of climatological modelling of air temperature and precipitation through GIS techniques. Int J Climatol 20:1823-1841

Phillips DL, Dolph J, Marks D (1992) A comparison of geostatistical procedures for spatial analysis of precipitations in mountainous terrain. Agric For Meteorol 58:119-141

Price DT, McKenney DW, Nalder IA, Hutchinson MF, Kesteven JL (2000) A comparison of two statistical methods for spatial interpolation of Canadian monthly mean climate data. Agric For Meteorol 101:81-94

Prudhomme C, Reed DW (1999) Mapping extreme rainfall in a mountainous region using geostatistical techniques: a case study in Scotland. Int J Climatol 19:1337-1356

Rajagopalan B, Lall U (1998) Locally weighted polynomial estimation of spatial precipitation. J Geogr Inf Decision Anal 2(2):44-51

Rivoirard J (1994) Introduction to disjunctive kriging and nonlinear geostatistics. Oxford Univesity Press, Oxford

Saveliev AA, Mucharamova SS, Piliugin GA (1998) Modeling of the daily rainfall values using surface under tension and kriging. J Geogr Inf Decision Anal 2(2):52-64

Tabios GQ, Salas JD (1985) A comparative analysis of techniques for spatial interpolation of precipitation. Water Resour Bull 21(3):365-380

Thiessen AH (1911) Precipitation averages for large areas. Mon Weather Rev 39(7):1082-1084

Thornton PE, Running SW, White MA (1997) Generating surfaces of daily meteorological variables over large regions of complex terrain. J Hydrol 190:214-251

Turkes M (1999) Vulnerability of Turkey to desertification with respect to precipitation and aridity conditions. Turk J Engin Environ Sci 23:363-380

Submitted: July 8, 2004; Accepted: November 25, 2004

Proofs received from author(s): December 30, 2004 